Material and method In this retrospective study, rate of abnormalities of TFT, its association with morbidities and neurodevelopment is investigated in 139 premature babies admitted to neonatal intensive care unit in Uludag Universitiy Medical Faculty between January 2009 and January 2012.

Results Mean gestational weeks and birth weights of infants were $31.3 \pm 2.9$ weeks $1667 \pm 707$ gr. Fourty one patients (24\%) had TFT abnormality, 53.6\% had transient TSH elevation, $22 \%$ had primary hypothyroidism, 22\% had non-thyroidal disease and $2.4 \%$ had transient hypothyroxinemia. Fourty seven percent of SGA babies and, 26\% of AGA babies had TFT abnormalities, difference was not statistically significant. Most common TFT abnormality was found to be transient TSH elevation in SGA and AGA babies. Mothers of 8 patients had maternal hypothyroidism. Five of these babies $(63.5 \%)$ had TFT abnormality $(p=0.049)$. Mean head circumference in 18 months of age in normal TFT group was $46.3 \mathrm{~cm} \pm 1.6$ compared to babies with abnormal TFT whose mean head circumference was $45 \mathrm{~cm} \pm 2.4$ at the same age, difference was statistically significant. There were no statistically significant difference between groups for antropometric values in 6, 9, 12 moths and neurodevelopmental evaluation.

Conclusion TFT abnormalities are frequent in prematüre babies and it is one of the most common causes of preventable mental retardation. In neonates, even transient hypothyroidism is associated with poor neurodevelopmental outcome, hence it must be treated urgently. As also detected in our study, maternal hypothyroidism is associated with increased neonatal hypothyroidism and these babies must be managed closely in postnatal period. Although not statistically significant, SGA babies were found to have increased rate of hypothyroidism. Further investigation with larger number of patients is necessary.

\section{PS-042C IS LOW-DOSE COMBINED ORAL CONTRACEPTIVES USE ASSOCIATED TO LOWER BONE MINERAL CONTENT VARIATION IN ADOLESCENTS OVER A ONE-YEAR PERIOD?}

${ }^{1}$ TB Goldberg, ${ }^{1}$ TP Biason, ${ }^{2} \mathrm{CS}$ Kurokawa, ${ }^{2} \mathrm{MR}$ Moretto, ${ }^{3} \mathrm{AS}$ Teixeira, ${ }^{4} \mathrm{HRC}$ Nunes. ${ }^{1}$ Department of Pediatrics - Adolescent Medicine Course - Graduate Program in Gynecology Obstetrics and Mastology, Botucatu School of Medicine - São Paulo State University (UNESP), Botucatu, Brazil; ${ }^{2}$ Clinical and Experimental Pediatrics Research Center - Department of Pediatrics, Botucatu School of Medicine - São Paulo State University (UNESP), Botucatu, Brazil; ${ }^{3}$ Department of Tropical Diseases and Diagnostic Imaging, Botucatu School of Medicine - São Paulo State University (UNESP), Botucatu, Brazil; ${ }^{4}$ Statistical Consultant, Botucatu School of Medicine - São Paulo State University (UNESP), Botucatu, Brazil

\subsection{6/archdischild-2014-307384.339}

Background Low dose combined oral contraceptives (COC) can interfere in bone mass acquisition during adolescence. To evaluate bone mineral density (BMD) and bone mineral content (BMC) in female adolescents taking a standard low-dose (EE 20 $\mu \mathrm{g} /$ Desogestrel $150 \mu \mathrm{g}$ ) combination oral contraceptive (COC) over a one-year period and compare with healthy adolescents from the same age group not taking COCs.

Methods A non-randomised parallel control study with one-year follow-up. Sixty-seven adolescents from 12 to 20 years of age, divided into COC users $(\mathrm{n}=41)$ taking $20 \mu \mathrm{g} \mathrm{EE} / 150 \mu \mathrm{g}$ Desogestrel and non-user controls $(n=26)$, were evaluated through bone densitometry examinations at baseline and 12 months later. Comparisons between groups at study start was done through the Mann-Whitney test with significance level fixed at 5\% or corresponding $\mathrm{p}$ value; comparisons between groups at study start and 12 months later used variations in median percentages for bone mass variables.

Results COC users presented low bone mass acquisition in the lumbar spine and BMD and BMC median variations between baseline and at 12 months of $2.07 \%$ and $+1.57 \%$ respectively whereas the control group presented variations of $+12.16 \%$ and $+16.84 \%$ for BMD and BMC, respectively, over the same period. The total body BMD and BMC presented similar evolution during the study in both groups. Statistical significance ( $p$ Conclusion The use of a low COC dose (EE $20 \mu \mathrm{g} /$ Desogestrel $150 \mu \mathrm{g}$ ) was associated to lower bone mass acquisition in adolescents during the study period.

Trial registration: (Register Number):RBR-5 h9b3c.

\section{Extreme Preterm Birth}

\section{PS-043 PERINATAL FACTORS ASSOCIATED WITH SURVIVAL IN INFANTS AT THE LIMIT OF VIABILITY}

${ }^{1}$ F García-Muñoz Rodrigo, ${ }^{2}$ A García-Alix Pérez, ${ }^{3} \mathrm{JA}$ García Hernández, ${ }^{2} \mathrm{JA}$ Figueras Aloy. ${ }^{1}$ Neonatology, Spanish SEN1500 Network, Las Palmas de Gran Canaria, Spain; ${ }^{2}$ Neonatology, Spanish SEN1500 Network, Barcelona, Spain; ${ }^{3}$ Obstetrics, Complejo Hospitalario Universitario Insular- Materno Infantil de Canarias, Las Palmas de Gran Canaria, Spain

\subsection{6/archdischild-2014-307384.340}

Background and aims Decisions in pregnancies at the limit of viability are usually taken primarily based on gestational age. Other factors, however, may be critical to the results. The aim of our study was to know which perinatal factors are associated with survival in neonates $\leq 26$ weeks GA.

Methods Retrospective analysis of prospectively collected data. We included all inborn infants $\leq 26$ weeks GA without major congenital malformations, admitted to the NICUs participating in the Spanish SEN1500 network, during the period 20042010. The relation of risk factors to the likelihood of survival was analysed with the Cox Proportional-Hazards Regression method.

Results During the study period 3,915 infants $\leq 26$ weeks GA were born alive. Of these, 3,518 (89,9\%) were "inborns". Infants who died in the delivery room and/or who had severe congenital malformations were excluded. Finally, 3,236 patients were included. After correcting for potential confounders, survival was related to the following antenatal and postnatal variables:

Conclusions GA, birth weight, female sex, antenatal steroid and single gestation are factors potentially known prenatally that are associate with a higher probability of survival. After birth, in the first $12 \mathrm{~h}$ after admission, the CRIB I score and the temperature

\begin{tabular}{llll} 
Abstract PS-043 Table 1 & & \\
\hline Variables & OR & $95 \% \mathrm{Cl}$ & $\mathbf{p}$ \\
\hline Gestational age & 1.665 & $1,507-1,839$ & $<0.001$ \\
Birth weight & 1.003 & $1,003-1,004$ & $<0.001$ \\
Antenatal steroids & 2.805 & $2,270-3,467$ & $<0.001$ \\
Sex (male) & 0.716 & $0,610-0,840$ & $<0.001$ \\
Multiple gestation & 0.697 & $0,588-0,826$ & $<0.001$ \\
Admission temperature & 1.397 & $1.222-1.597$ & $<0.001$ \\
CRIB score I & 0.845 & $0.815-0.876$ & $<0.001$ \\
\hline
\end{tabular}

